\title{
Determinantes da desigualdade salarial entre as carreiras do governo de Minas Gerais
}

\author{
Rodolfo Pinhón Bechtlufft 1
}

Bruno Lazzarotti Diniz Costa 1

1 Fundação João Pinheiro / Escola de Governo, Belo Horizonte / MG - Brasil

Este artigo analisa os determinantes do diferencial de remuneração entre as carreiras do Poder Executivo do estado de Minas Gerais, utilizando um modelo de regressão linear cujas variáveis explicativas foram elaboradas com base em diferentes abordagens teóricas acerca da determinação dos salários: teoria do capital humano, teoria da segmentação dos mercados, teoria da discriminação e sociologia das profissões, além de considerar as especificidades do setor público. A escolha da unidade federativa se justifica pela relevância no cenário nacional e pela difícil situação fiscal vivenciada nos últimos anos. A investigação é guiada pela hipótese de que as diferenças salariais no setor público refletem não só a qualificação e a experiência no trabalho, mas também reproduzem distorções típicas das estruturas socioeconômicas e político-burocráticas. Os resultados corroboram a hipótese adotada e sugerem que a estrutura relativa de salários no setor público constitui uma manifestação concreta das diferenças de recursos políticos disponíveis às carreiras, do prestígio social das profissões e de aspectos estruturais da desigualdade de gênero.

Palavras-chave: desigualdade salarial; setor público; política de remuneração; carreiras.

\section{Determinantes de la desigualdad salarial entre las carreras del Gobierno de Minas Gerais}

Este artículo investiga los determinantes del diferencial de remuneración entre las carreras del Poder Ejecutivo del estado de Minas Gerais, utilizando un modelo de regresión lineal cuyas variables explicativas fueron planteadas a partir de diferentes enfoques teóricos de la determinación de los salarios: teoría del capital humano, teoría de la segmentación del mercado, teoría de la discriminación y sociología de las profesiones, además de considerar las especificidades del sector público. La elección de la unidad federativa se justifica por su relevancia en el escenario nacional y por la difícil situación fiscal observada en los últimos años. La hipótesis que guía la investigación es que las diferencias salariales en el sector público reflejan no solo la calificación y la experiencia laboral, sino que también reproducen distorsiones propias de las estructuras socioeconómicas y político-burocráticas. Los resultados corroboran la hipótesis adoptada y sugieren que la estructura salarial relativa en el sector público constituye una manifestación concreta de las diferencias en los recursos políticos disponibles para las carreras, el prestigio social de las profesiones y los aspectos estructurales de la desigualdad de género.

Palabras clave: desigualdad salarial; sector público; política de remuneraciones; carreras.

\section{Determinants of salary inequality between Minas Gerais government careers}

This research investigates the determinants of salary differences among Minas Gerais government careers using a linear regression model. Explanatory variables were raised from different theoretical approaches to determine the salaries: human capital theory, market segmentation theory, discrimination theory, and sociology of professions, in addition to considering the specificities of the public sector. The choice of the Brazilian state of Minas Gerais is justified by its relevance in the country and the fiscal crisis experienced in recent years. The hypothesis is that salary differences in the public sector not only express education and work experience, but also typical distortions of socioeconomic and political-bureaucratic structures. The results corroborate the hypothesis and suggest that the relative salary structure in the public sector constitutes a concrete manifestation of the differences in political resources available to careers, the social prestige of professions, and structural aspects of gender inequality.

Keywords: salary inequality; public sector; remuneration policy; careers. 


\section{INTRODUÇÃO}

Nos últimos anos, diante da crise fiscal do Estado brasileiro, o tema das remunerações no setor público foi recolocado no centro do debate político nacional. Entre os esforços recentes de contenção dos gastos públicos, destaca-se a Emenda Constitucional no 95, de 2018, que estabelece o Teto dos Gastos Públicos e a Reforma da Previdência. Mais recentemente, a Emenda Constitucional no 109 , de 2021, estabeleceu condições para a vedação de reajustes aos salários dos servidores públicos. Nesse contexto, argumentos que criticam os elevados salários do funcionalismo público, sem levar em conta a heterogeneidade de categorias profissionais que o constituem, são frequentes na mídia e no debate público.

Apesar disso, os trabalhos que analisam as disparidades salariais no setor público são escassos na literatura acadêmica recente (Ventura \& Cavalieri, 2021), e a maioria enfoca as distorções entre os salários dos setores público e privado (Marconi, 2001; Souza \& Medeiros, 2013; Vaz \& Hoffmann, 2007). Ademais, embora os governos municipais e estaduais sejam responsáveis por mais de $90 \%$ dos vínculos públicos no Brasil (Instituto de Pesquisa Econômica Aplicada [Ipea], 2018), poucas análises empíricas buscam compreender a desigualdade salarial nos governos subnacionais.

Este artigo tem como objetivo investigar os determinantes da desigualdade salarial no Poder Executivo de Minas Gerais. Entre as 27 unidades da federação, o governo mineiro é o segundo maior, tanto em número de servidores quanto em orçamento (Ipea, 2018). Além disso, a escolha do estado se justifica por se tratar de um exemplo do padrão de comportamento observado nos governos estaduais nos últimos anos, em que o crescimento das despesas com pessoal ativo é explicado mais por elevações nos salários do que pela contratação de novos servidores públicos (Santos, Cavalcante, Martins, Lacerda \& Schettini, 2016). Ademais, o governo de Minas Gerais registrou, em 2020, o segundo maior percentual de gastos com pessoal em relação à receita corrente líquida (Secretaria do Tesouro Nacional, 2021), com valores que extrapolam o limite máximo estabelecido na Lei de Responsabilidade Fiscal.

Este artigo foi motivado ainda pelo relevante impacto que a distribuição de rendimentos do funcionalismo público exerce na desigualdade econômica da sociedade como um todo. Diversos estudos apontam que os rendimentos do funcionalismo público caminharam na contramão da tendência de queda da desigualdade observada no Brasil durante os anos 2000, graças ao crescimento da participação dos rendimentos do funcionalismo público na renda total da sociedade e à intensificação da concentração interna desses rendimentos (Daré, 2011; Hoffmann, 2013; Souza, Bessa, Margonato \& Ferreira, 2017).

A hipótese que orienta o artigo é a de que as diferenças de remuneração no setor público expressam não apenas a qualificação e a experiência dos servidores, mas também são influenciadas pelos recursos políticos mobilizados pelas categorias profissionais do Estado e reproduzem aspectos estruturais da desigualdade social brasileira. Para explorá-la, foi feita uma análise quantitativa da relação entre a remuneração das carreiras e seus principais determinantes, levantados com base em revisão teórica a respeito da determinação dos salários na economia e considerando as especificidades do setor público. O efeito de cada variável selecionada foi estimado por meio de um modelo de regressão linear que utilizou o método dos mínimos quadrados ordinários.

Além da Introdução e da Conclusão, este artigo tem três seções. A próxima seção apresenta uma revisão da literatura sobre determinação dos salários, destacando aspectos específicos do funcionalismo público no Brasil, seguida por uma análise da evolução recente da distribuição de rendimentos do Poder 
Executivo de Minas Gerais. A terceira apresenta a metodologia para coleta de dados e a especificação do modelo de regressão utilizado. Por fim, a quarta seção interpreta os resultados encontrados.

\section{DETERMINANTES DA REMUNERAÇÃO DAS CARREIRAS NO SERVIÇO PÚBLICO}

Diferenças de salários são explicadas por diversas razões, relacionadas com as características individuais dos trabalhadores, a natureza do posto de trabalho, o poder de negociação dos funcionários, o processo histórico de estratificação social, entre outros fatores. Uma das explicações para as diferenças salariais na economia considera que trabalhadores distintos têm diferentes níveis de produtividade, influenciados tanto por características inatas quanto por fatores adquiridos ao longo da vida, como treinamento, experiência e educação formal. Supondo que maiores níveis de escolaridade aumentem a produtividade dos indivíduos, espera-se que haja uma correlação positiva entre os salários e o grau de instrução formal do trabalhador, o que de fato ocorre. Tal relação constitui um dos padrões empíricos mais bem estabelecidos na literatura de economia do trabalho e da educação (Fernandes, 2002).

Não há um consenso, no entanto, para explicar essa correlação. Uma das hipóteses explicativas mais difundidas é a teoria do capital humano. O conceito de "capital humano" pode ser entendido como o estoque de habilidades e conhecimentos que os indivíduos adquirem e que geram aumentos na renda futura. Segundo essa abordagem, há dois tipos básicos de capital humano: o geral, adquirido pela educação formal, e o específico, adquirido no próprio mercado de trabalho. A teoria adota a hipótese de que os investimentos em educação e treinamento aumentam a produtividade dos trabalhadores, que, por sua vez, determinam salários maiores (Woodhall, 1987).

Críticos da teoria do capital humano, contudo, argumentam que a correlação entre escolaridade e renda pode se explicar por outras razões. Entre elas, destaca-se a hipótese da triagem, que defende que a educação formal cumpre fundamentalmente o papel de certificar ou filtrar indivíduos que têm determinadas características pessoais valorizadas pelos empregadores, como respeito à hierarquia e cumprimento das normas. Outra corrente, mais sociológica, afirma que a escolaridade também sinaliza aos empregadores posições de classe e de status social, visto que os trabalhadores mais qualificados têm maior probabilidade de serem indivíduos originados de classe ou de status social mais elevados. Para Collins (1971), o discurso meritocrático de que os indivíduos mais qualificados seriam mais produtivos e, por essa razão, teriam acesso a maiores remunerações é, em parte, resultado de uma instrumentalização ideológica dos grupos de status elevados como estratégia para a distinção e a ascensão social em relação aos grupos subalternos.

De todo modo, parte significativa da desigualdade salarial não pode ser explicada só por diferenças de escolaridade, experiência ou outros atributos geralmente associados à produtividade dos indivíduos. Assim, diversos autores discutem a desigualdade salarial dando maior ênfase a determinantes institucionais, políticos e culturais.

Uma dessas abordagens, conhecida como segmentação dos mercados, parte da ideia de que existem diferentes mercados de trabalho, com regras de operação distintas, as quais se referem às formas de contratação, remuneração e promoção que regem os mercados. Alguns deles têm boas condições de trabalho, com salários elevados, sistemas de promoção na carreira e estabilidade. Já outros mercados são caracterizados por informalidade, baixos salários, instabilidade e ausência de sistemas de progressão na carreira. Para explicar as diferenças entre os mercados de trabalho, autores dessa abordagem apontam como causas o poder de barganha dos trabalhadores e a existência de leis que regulam o mercado de trabalho, o que gera setores mais ou menos protegidos por essas leis (Fernandes, 2002; Marconi, 2001). 
Outra contribuição importante foi dada pela "sociologia das profissões". Segundo Santos, a linha weberiana da sociologia das profissões reúne autores cujo tema comum é o poder dos grupos profissionais. Para eles, as profissões se estabelecem ao mesmo tempo como unidade integradora e excludente, cumprindo a dupla função de fechar os grupos profissionais em si e estabelecer a competição com outros grupos. O poder das profissões estaria na capacidade de doar sentido aos que pertencem ao grupo profissional e estabelecer a dominação de um grupo sobre outros e sobre a sociedade (Santos, 2011, p. 31).

A profissionalização é uma estratégia de luta por remuneração, poder e prestígio, cujo processo de consolidação impõe a dominação de determinados grupos profissionais sobre os demais e inaugura uma nova forma de desigualdade estrutural. Tal estratégia se desenvolve tanto no âmbito econômico, em busca de proteção e monopólio legal, quanto no campo sociossimbólico, promovendo o status social da profissão. Desse modo, um importante elemento de poder das profissões reside na capacidade de produzir uma base cognitiva e técnica aliada à criação de barreiras à entrada no mercado de trabalho. Os grupos profissionais bem-sucedidos conseguem ditar as regras do jogo social, controlando o acesso às profissões por meio de reivindicações da expertise, isto é, da base cognitiva e técnica criada e controlada por esses grupos (Larson, 1977, como citado em Santos, 2011).

A esse respeito, Coelho (1999) analisa três ocupações que, historicamente no Brasil, reforçaram suas posições de status e poder frente às demais profissões: medicina, direito e engenharia. Na visão do autor, o credencialismo acadêmico validado pelo aparato estatal foi um dos principais instrumentos de garantia do status dessas ocupações, cujos privilégios tendem a se refletir também na remuneração das carreiras no serviço público. Entre elas, como ressalta Bonelli (2003), as carreiras vinculadas ao direito merecem destaque, seja pela afinidade com o aparelho de Estado, seja pelo grau de diferenciação dentro da mesma lógica profissional, ou ainda pelo fato de a profissionalização concorrer com outros processos. Segundo a autora, a conformação das carreiras jurídicas no Estado brasileiro varia e se estratifica de acordo com a forma como combinam profissionalismo com burocratização, apresentando diferentes níveis de autonomia e interdependência em relação à política, ao mercado e às autoridades do campo profissional. Assim, enquanto os ministros do Supremo Tribunal Federal têm de se haver mais diretamente com a política, os procuradores de Justiça vêm ganhando status profissional desde a Constituição de 1988, ao passo que delegados de polícia permanecem no nível mais baixo de autonomia e profissionalização, já que continuam expostos a remoções e transferências.

Por fim, outra fonte de diferenciação de salários tem relação com a discriminação social. A divisão sexual do trabalho, o racismo e outros tipos de preconceitos sociais são exemplos de fatores estruturais de discriminação que se mesclam com outros determinantes da desigualdade no mercado de trabalho. Segundo Marconi (2001), há uma persistência de condições desvantajosas de inserção e de permanência no mercado de trabalho para os grupos historicamente marginalizados na estrutura social, que pode ser constatada mesmo quando a estimativa da renda é controlada por outras características, como escolaridade, idade e ocupação.

Entre as teorias citadas, a abordagem da segmentação dos mercados tem elementos importantes para a compreensão da dinâmica de determinação dos salários do poder público, uma vez que o setor público pode ser analisado como um bloco distinto, regido por normas próprias. Em primeiro lugar, o Estado se diferencia da maioria dos empregadores do setor privado porque a busca pelo lucro não é um objetivo essencial das unidades governamentais, o que torna inadequada a tentativa de explicação dos salários pagos pelo governo por meio de modelos econômicos que se baseiam no pressuposto da maximização do lucro. 
Ademais, há um importante conjunto de regras e princípios próprios do funcionalismo público brasileiro, cuja configuração atual está essencialmente relacionada com o processo histórico de consolidação do aparato administrativo burocrático do Estado. Segundo Pacheco (2010), o Brasil foi o primeiro país latino-americano a iniciar a constituição de corpos permanentes de Estado baseada no modelo burocrático weberiano. ${ }^{1}$ Já na década de 1930, o governo brasileiro propôs a adoção do concurso público, a estabilidade no emprego e a organização de carreiras ${ }^{2}$ como regras de organização do serviço público.

Historicamente, todavia, a formação da burocracia pública brasileira tendeu a um dualismo que combinava núcleos de burocracia qualificada com amplos setores de baixa qualificação e vulneráveis às práticas de clientela e patronagem (Abrucio \& Loureiro, 2018; Cavalcante \& Carvalho, 2017). Por outro lado, desde a Constituição de 1988, é possível perceber um aprofundamento da profissionalização da burocracia, incluindo melhorias da qualificação, remuneração, maior participação de servidores efetivos em cargos comissionados e maior equilíbrio de gênero (Cavalcante \& Carvalho, 2017). Com a Constituição, o concurso público foi efetivamente institucionalizado como norma geral de acesso aos quadros de pessoal. Ainda que existam modelos distintos de entrada e de permanência no serviço público, como os cargos celetistas, de recrutamento amplo e os contratos temporários, o regime estatutário dos servidores concursados é o tipo de vínculo mais representativo, correspondendo a 87,6\% dos servidores (Ipea, 2018), além de ser o grupo que expressa as características mais típicas do funcionalismo público no Brasil. Eles têm arcabouço legal próprio, baseado nos princípios constitucionais da "isonomia" e da "impessoalidade", segundo os quais todas as pessoas devem ser regidas indistintamente pelas mesmas regras (Pacheco, 2010).

Dessa forma, há pouca flexibilidade para atribuir remunerações diferentes de acordo com o desempenho de cada servidor. Os critérios para progressões salariais são formalmente definidos e se aplicam automaticamente a todos os servidores de determinada carreira, em geral associados ao nível de escolaridade e ao tempo de serviço (Pacheco, 2010). Segundo Marconi (2001), a estrutura de salários no serviço público exibe muitas distorções e pouca racionalidade, causadas por fatores como os reposicionamentos automáticos de servidores, as incorporações de ganhos decorrentes de decisões judiciais e outros ganhos possibilitados por interpretações distintas das leis, que muitas vezes se tornam possíveis em virtude do emaranhado jurídico em que se transformou a legislação de pessoal no setor público.

O fortalecimento e a autonomia de determinadas carreiras mostram sua face problemática quando combinados com um crescente corporativismo, ativismo judicial e judicialização da política. Em vários âmbitos, esses processos têm exposto o problema do controle político sobre a burocracia (Olivieri, 2011) e da captura do Estado pelos interesses dos burocratas, os quais muitas vezes se expressam em ganhos desproporcionais de remuneração.

Abrucio, Pedroti e Pó (2010) afirmam que boa parte das legislações implementadas no serviço público após a Constituição de 1988 resultou em aumento do corporativismo estatal. Entre elas, pode-se

\footnotetext{
${ }^{1}$ A tipologia weberiana clássica define a burocracia como um tipo ideal de organização baseado na racionalidade dos processos e legitimado por normas legais previamente estabelecidas. Entre as características do modelo burocrático, cabe aqui destacar a hierarquia de autoridade e a constituição de um corpo de funcionários especializados, cujas formas de seleção, remuneração e promoção são definidas por critérios formais e impessoais que, pelo menos em tese, deveriam refletir a competência técnica e o princípio da meritocracia. ${ }^{2}$ Segundo Modesto (2016), a carreira pública pode ser definida como "uma unidade hierarquizada de cargos públicos afins", estruturada em níveis e graus ascendentes de responsabilidade e remuneração. Assim, os cargos de carreira se diferenciam dos isolados, pois as carreiras são organizadas hierarquicamente em patamares de progressão e de promoção funcional, enquanto os cargos isolados não ensejam o percurso progressivo do servidor.
} 
destacar o crescimento da parcela de gratificações e de outros benefícios na remuneração básica de muitas carreiras, cuja incorporação depende "mais da força política de cada setor do que do mérito medido por avaliações de desempenho" (Abrucio et al., 2010, p. 58). Ao analisar o período de 1995 a 2014, Cavalcante e Carvalho (2017) destacam que o processo de recomposição salarial das carreiras federais se deu de maneira bastante desigual, resultando num aprofundamento da desigualdade na remuneração entre distintos cargos e carreiras.

Por essas razões, a análise dos recursos de poder das carreiras é um fator essencial para compreender as disparidades de remuneração no setor público. Segundo Gouvêa (1994, p. 31), tais recursos advêm da "capacidade de atuar na definição das regras do jogo institucional e na definição de políticas", que, por sua vez, variam de acordo com o momento histórico e as relações que se estabelecem no interior do Estado. Tal capacidade está relacionada não somente com a qualificação técnica e as informações que os burocratas detêm a respeito do Estado, mas também com o status, as formas de organização política e as ligações estabelecidas com o poder central. Uma vez que esses recursos de poder são acessados e mobilizados de forma distinta pelos diferentes segmentos burocráticos, cada um deles tem maior ou menor capacidade de influenciar as decisões políticas que atendem às reivindicações do grupo. Portanto, as diferenças de poder entre segmentos do corpo burocrático configuram estratificações na estrutura administrativa do Estado, e as variações salariais podem ser interpretadas, ainda que parcialmente, como uma manifestação dessas estratificações.

Sobre isso, Marconi (2010) aponta três razões de natureza política que podem influenciar a determinação dos salários no funcionalismo público: o tamanho das carreiras, a natureza da atividade desempenhada e o grau de acesso ao poder decisório. Assim, espera-se que as carreiras mais numerosas, mais próximas do núcleo central do governo, e aquelas que desempenham atividades essenciais e exclusivas de Estado tenham maior poder e capacidade de influenciar as decisões que acarretem benefícios para seus servidores.

Em relação ao tamanho, embora os grupos maiores tenham maior potencial de exercer pressão política sobre os governantes, é preciso considerar que os aumentos remuneratórios concedidos a eles têm maior impacto financeiro nas contas do governo. Assim, a disponibilidade de recursos fiscais pode se tornar uma restrição à concessão de benefícios para carreiras mais numerosas. Além disso, a capacidade de exercer pressão política depende não só do tamanho, mas também do grau de coesão e da atuação sindical.

Já o poder das carreiras que realizam atividades essenciais e exclusivas está relacionado com a dependência do Estado em relação às funções por elas desempenhadas e o caráter monopolista das carreiras, uma vez que elas não têm correspondência no setor privado. Segundo Bresser-Pereira (1998), as atividades exclusivas são aquelas que só o Estado pode realizar, como definir as leis, impor a Justiça, manter a ordem, policiar, defender o país, representá-lo no exterior, arrecadar impostos, regulamentar atividades econômicas e fiscalizar o cumprimento das leis. Ao lado das funções essenciais do Estado, Fernandes e Palotti (2019) identificam uma tendência à diversificação da burocracia federal, com a criação de novas carreiras dedicadas a funções emergentes, o que resultou num desenvolvimento desigual e assimétrico entre as carreiras novas e tradicionais.

Por sua vez, o acesso das carreiras ao núcleo decisório do governo é um recurso político que se expressa, de forma geral, no acesso aos cargos de alto escalão do Poder Executivo. Os especialistas em políticas públicas e gestão governamental do governo federal, segundo se depreende de Monteiro (2013), buscam conciliar a profissionalização da carreira com a participação em posições de poder como estratégias que se reforçam mutuamente. A capacidade que uma carreira tem de influenciar 
as decisões do governo pode ocorrer também pela via da representação política no âmbito do Poder Legislativo. Muitas vezes, graças à fragmentação do sistema partidário brasileiro e à necessidade de construir uma base majoritária de apoio no Legislativo, os cargos de alto escalão da burocracia estatal são usados como moeda de troca entre os partidos políticos para estabelecer o arranjo que ficou conhecido como governo de coalizão (Abrucio \& Loureiro, 2018). Pode haver ainda, por hipótese, a influência mais direta exercida por filiados partidários na definição dos quadros da burocracia decisória. Entretanto, como demonstram Lopez e Silva (2019), em nível federal, a participação de filiados é minoritária, mesmo nos cargos de poder político-administrativo mais elevados. Assim, ainda que existam conexões entre atores político-partidários que influenciam as nomeações dos cargos de alto escalão, provavelmente elas são mediadas por outros aspectos relacionais e por fatores extrapartidários de influência, posicionamento e prestígio internos ao aparelho de Estado.

Por fim, não se pode ignorar o papel dos governantes na concessão dos reajustes salariais. Se, por um lado, as carreiras têm recursos capazes de influenciar as decisões de governo, por outro, os governantes apresentam diferentes ideologias e objetivos, que, a depender do modelo de gestão adotado e das pautas consideradas prioritárias, influenciarão a concessão de reajustes salariais e a própria definição de quais são as carreiras estratégicas e com maior acesso ao poder central (Pacheco, 2010).

O quadro abaixo sintetiza as principais correntes teóricas abordadas nesta seção, as quais explicam as diferenças salariais na economia e no setor público brasileiro.

\section{QUADRO 1 SÍNTESE TEÓRICA}

\begin{tabular}{|c|c|}
\hline Teoria/Abordagem & Resumo \\
\hline Teoria do capital humano & $\begin{array}{l}\text { Por meio da educação formal e do treinamento profissional, indivíduos acumulam conhecimentos } \\
\text { e habilidades que os tornam mais produtivos e aumentam seus salários. }\end{array}$ \\
\hline Teoria da segmentação & $\begin{array}{l}\text { Existem diferentes mercados de trabalho, com regras de operação distintas. A legislação } \\
\text { trabalhista, a forma de organização sindical, o poder de barganha dos trabalhadores e } 0 \\
\text { ambiente em que ocorrem as negociações salariais são fatores que influenciam a determinação } \\
\text { dos salários. }\end{array}$ \\
\hline Teoria da discriminação & $\begin{array}{l}\text { Fatores culturais e estruturais de discriminação social, como a divisão sexual do trabalho, } 0 \\
\text { racismo e outros tipos de preconceitos sociais, explicam a persistência de condições salariais } \\
\text { desvantajosas para grupos sociais historicamente marginalizados. }\end{array}$ \\
\hline Sociologia das profissões & $\begin{array}{l}\text { As diferentes profissões adotam estratégias de disputa por remuneração, poder e prestígio } \\
\text { social, com maior ou menor grau de sucesso, o que implica uma desigualdade estrutural entre } \\
\text { os grupos profissionais. }\end{array}$ \\
\hline $\begin{array}{l}\text { Especificidades do setor } \\
\text { público }\end{array}$ & $\begin{array}{l}\text { As diferenças de poder entre as carreiras públicas configuram estratificações na estrutura } \\
\text { administrativa do Estado, que se refletem nas diferenças salariais. Entre os fatores políticos } \\
\text { que podem influenciar a remuneração das carreiras, destacam-se a natureza da atividade } \\
\text { desempenhada, a proximidade ao poder decisório e o tamanho das carreiras. }\end{array}$ \\
\hline
\end{tabular}

Fonte: Elaborado pelos autores. 


\subsection{Minas Gerais como Lócus Empírico: Disparidades de Remuneração no Poder Executivo Estadual}

No Poder Executivo de Minas Gerais, embora o número de servidores ativos tenha permanecido relativamente constante no período de 2009 a 2017, o gasto com pessoal ativo apresentou um aumento real per capita de cerca de 50\%, valor muito superior ao crescimento do salário-mínimo no mesmo período, como mostra o Gráfico 1.

\section{GRÁFICO 1 VARIAÇÃO DO GASTO COM PESSOAL ATIVO NO PODER EXECUTIVO ESTADUAL (MG)}

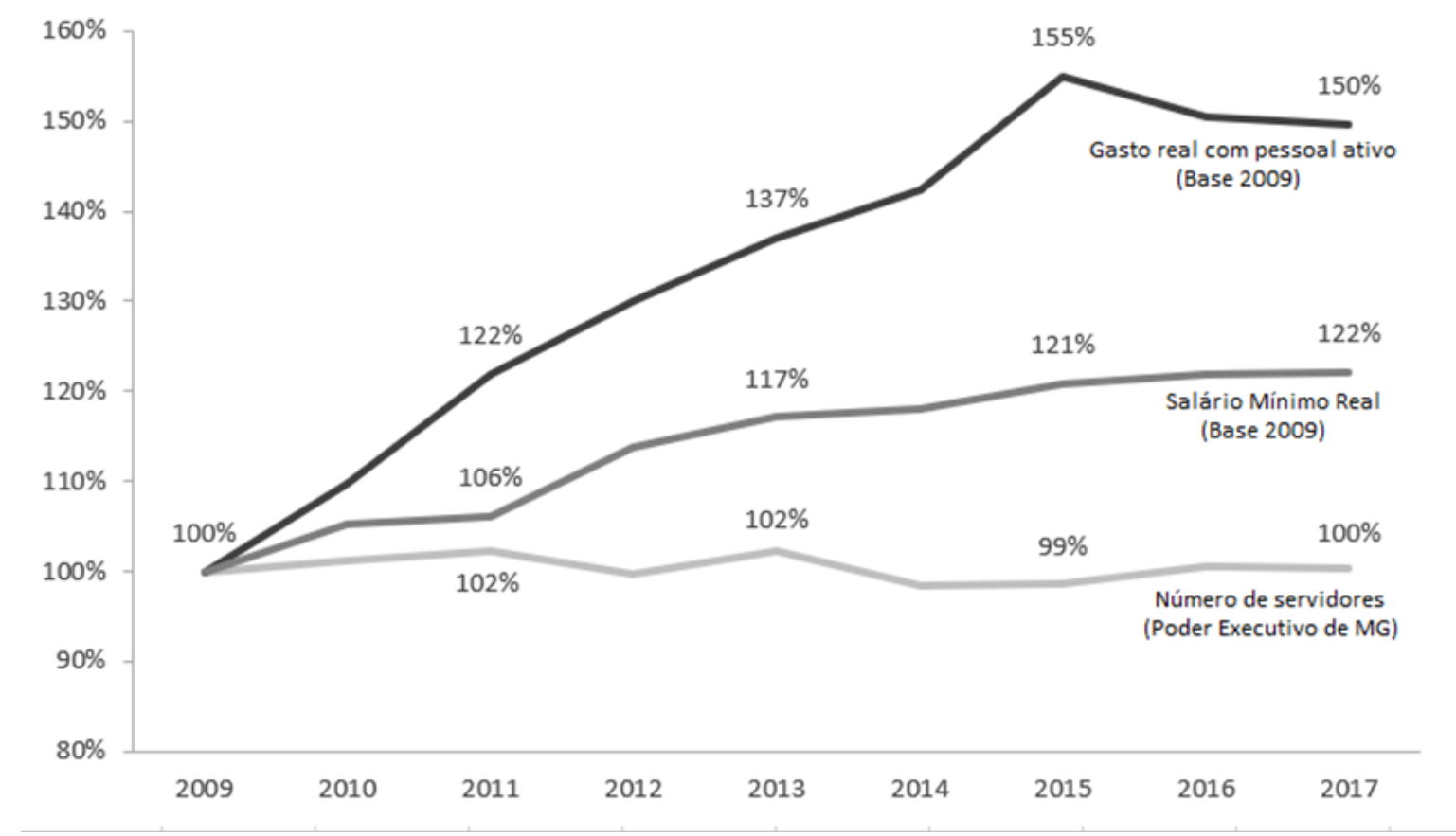

Índice de deflação: IPCA, ano-base: 2009.

Fonte: Elaborado pelos autores com base em dados do Portal da Transparência (MG) e do Ipea (2018).

Para analisar a trajetória da desigualdade de rendimentos no funcionalismo público do governo de Minas Gerais, o Gráfico 2 apresenta o índice de Gini calculado para dois grupos distintos: o conjunto dos servidores do Estado e, posteriormente, apenas os servidores civis, isto é, excluindo os militares. ${ }^{3}$ Nota-se que o Gini total aumentou no período de 2012 a 2015, mas reduziu nos dois anos subsequentes, apresentando nova elevação no último ano do período analisado. A comparação entre as duas linhas mostra que o índice calculado só para os civis era mais elevado do que o índice englobando civis e militares, mas esse padrão se inverteu a partir de 2014.

\footnotetext{
${ }^{3} \mathrm{O}$ índice de Gini é muito usado para mensurar a desigualdade na distribuição de rendimentos. Ele varia entre 0 e 1, em que os extremos representam, respectivamente, a situação de completa igualdade de renda e a situação oposta, na qual toda a renda está nas mãos de apenas um indivíduo. Quanto mais próximo de 1, maior é a desigualdade. Para o cálculo do Gini, foi considerada a remuneração bruta básica dos servidores, deduzido os abatimentos pelo teto constitucional e acrescido os jetons.
} 
GRÁFICO 2 EVOLUÇÃO DO ÍNDICE DE GINI DAS REMUNERAÇÕES DO PODER EXECUTIVO ESTADUAL (MG)

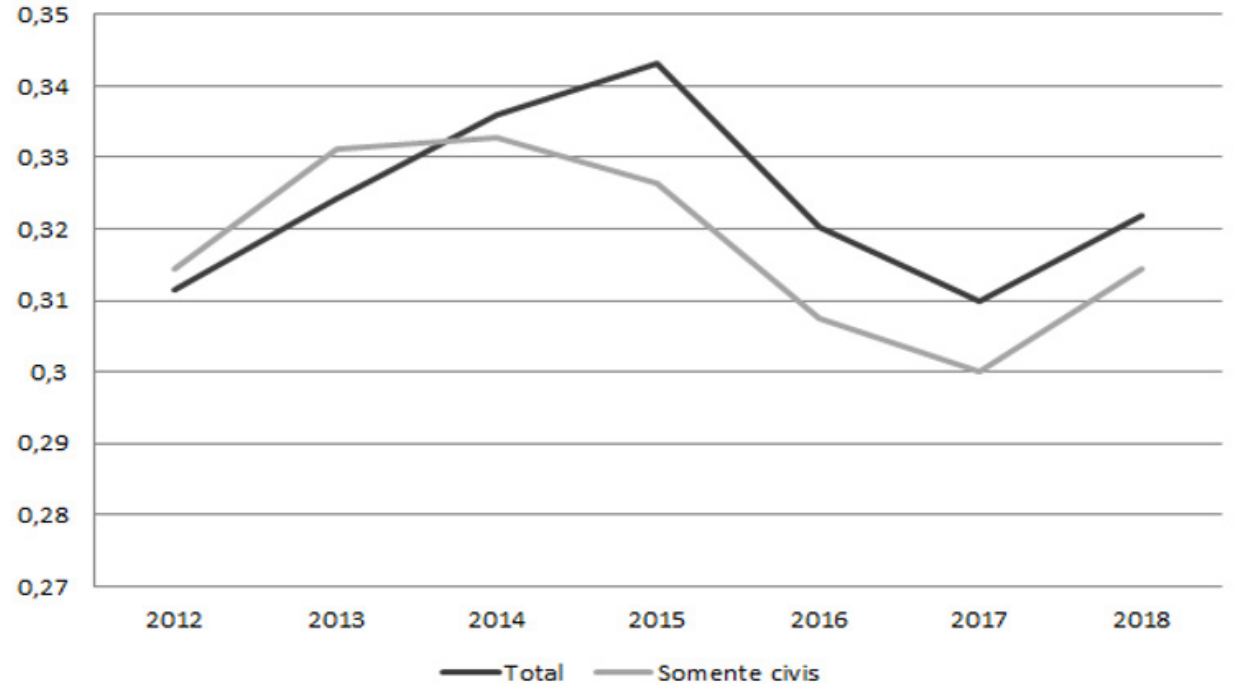

Fonte: Elaborado pelos autores com base em dados do Portal da Transparência (MG).

Para interpretar essas variações no Gini, é importante observar o comportamento das maiores carreiras do governo, pois elas têm maior impacto no resultado do indicador. Embora o Poder Executivo do estado de Minas Gerais conte com mais de 140 carreiras, somente três delas são responsáveis por mais de 65\% dos servidores: professores de educação básica, militares da Polícia Militar e do Corpo de Bombeiros e auxiliares serviços de educação básica, que representam, respectivamente, cerca de $40 \%$, $15 \%$ e $12 \%$ dos servidores do governo estadual. Em relação a essa composição, o período analisado não foi marcado por mudanças substanciais, como mostra o Gráfico 3.

\section{GRÁFICO 3 PERCENTUAL DE SERVIDORES DAS MAIORES CARREIRAS DO PODER EXECUTIVO ESTADUAL (MG) EM RELAÇÃO AO TOTAL}

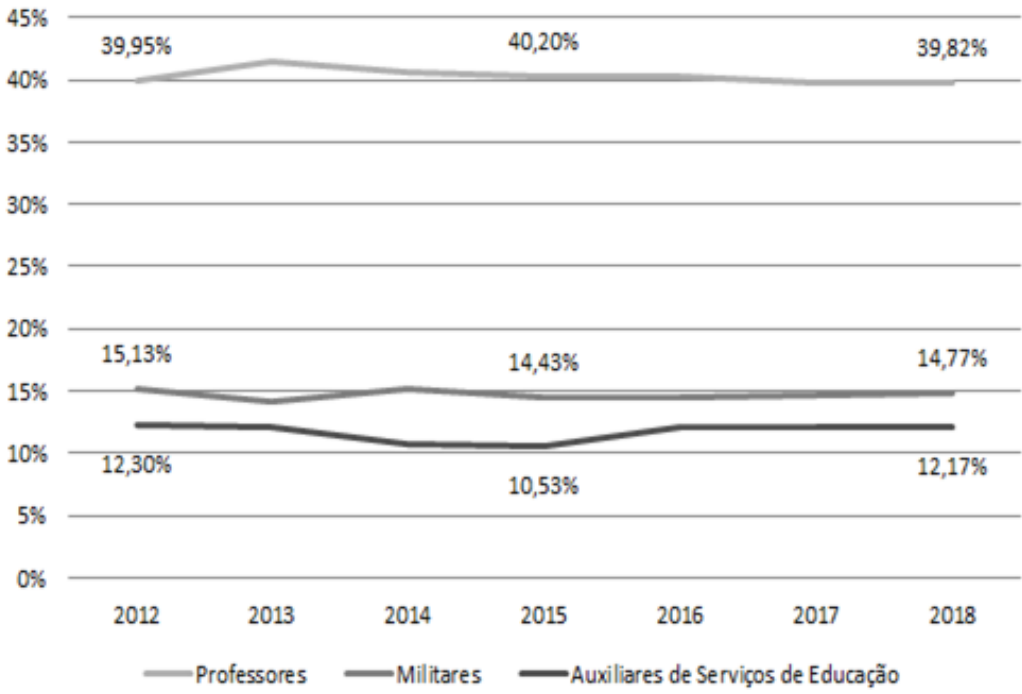

Fonte: Elaborado pelos autores com base em dados do Portal da Transparência (MG). 
Já em relação à remuneração, mudanças substanciais a partir de 2011 ajudam a explicar as variações do Gini. Em primeiro lugar, a Lei Estadual no 19.576 estabeleceu reajustes salariais progressivos para os militares, escalonados anualmente até o ano de 2015, o que representou um aumento nominal total de $100,73 \%$ na remuneração básica dessa categoria. O Gráfico 4 mostra que esses reajustes aumentaram, de modo substancial, a distância entre a remuneração média dos militares e a remuneração média dos demais servidores. Já em relação aos professores e aos auxiliares de serviços de educação básica, nota-se que a defasagem de suas remunerações em relação à remuneração média total cresceu de 2013 a 2015, mas foi um pouco recuperada após as aprovações das Leis n 21.710, de 2015, e 22.062, de 2016, que aumentaram a remuneração das carreiras da educação.

\section{GRÁFICO 4 REMUNERAÇÃO-HORA MÉDIA DAS MAIORES CARREIRAS DO PODER EXECUTIVO ESTADUAL (MG)}

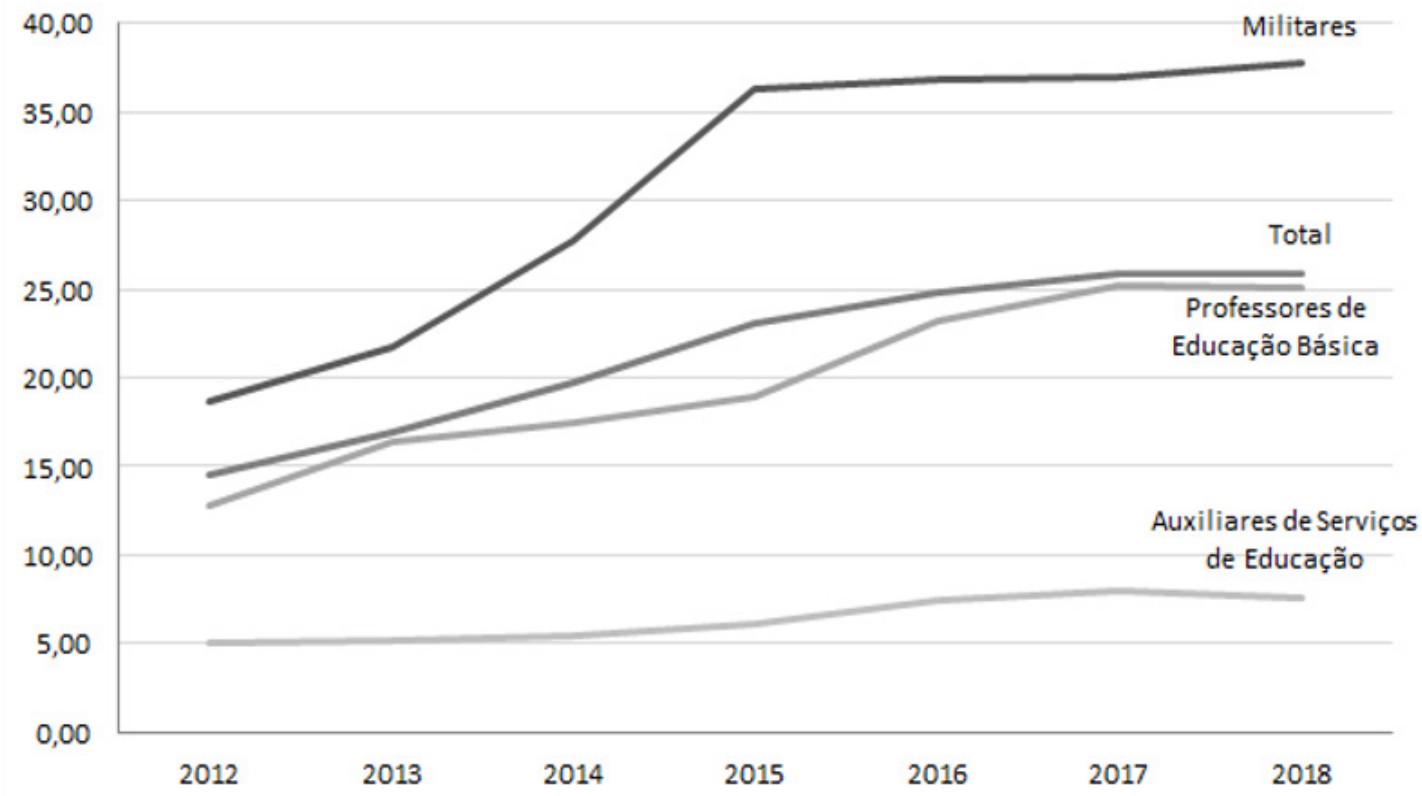

Fonte: Elaborado pelos autores com base em dados do Portal da Transparência (MG).

Observa-se, portanto, que o período de aumento do Gini, isto é, de 2012 a 2015, coincide com os anos de reajuste salarial dos militares. Em contraposição, a queda do Gini observada nos anos seguintes coincide com os aumentos remuneratórios das carreiras da educação básica, que contribuíram para uma redução na desigualdade de rendimentos entre os servidores estaduais. Contudo, uma análise mais detalhada a respeito das disparidades de remuneração entre as carreiras deve considerar as diferenças de escolaridade, tempo de serviço e outros determinantes dos vencimentos no setor público, tema que será abordado nos próximos tópicos. 


\section{MATERIAL E MÉTODOS}

Para investigar a relação entre a remuneração das carreiras e seus determinantes, foi proposto um modelo de regressão linear múltipla, que usou o método dos mínimos quadrados ordinários para estimar o efeito líquido das variáveis explicativas. Trata-se de uma análise de corte transversal, cujas informações se referem a setembro de 2018. A escolha do recorte temporal se justifica por ser o período mais recente com disponibilidade de dados completos, no momento da realização da pesquisa, e pelo fato de ser um mês típico do calendário escolar, que não é afetado pelas demissões de professores designados nos períodos de férias escolares.

Na literatura sobre determinação dos salários, há uma vasta quantidade de pesquisas baseadas no modelo salarial de Mincer, em que os rendimentos do trabalho são explicados pela escolaridade, pela experiência e por outras características individuais específicas, como gênero e raça. Em relação à forma funcional, tais pesquisas costumam adotar um modelo em que a renda é transformada em seu logaritmo natural, que pode ser expresso pela seguinte equação: $\ln w=\beta_{0}+\beta_{1}$ educ $+\beta_{2} \exp +\beta_{3} X+\mu$.

$\mathrm{Na}$ fórmula acima, $w$ se refere à renda do trabalhador, educ se refere aos anos de estudo, exp se refere à idade do trabalhador ou aos anos de experiência no trabalho, $X$ é um termo genérico utilizado para representar alguma característica específica do trabalhador, como gênero ou raça, e $\mu$ é a expressão de erro aleatório.

Ao contrário das equações de Mincer, o modelo utilizado neste artigo não se propõe a investigar as diferenças individuais, e sim as desigualdades entre as categorias profissionais do Estado, o que leva a uma mudança na unidade de análise: no lugar dos indivíduos, as carreiras.

Quanto à amostra selecionada, optou-se por considerar apenas as carreiras com pelo menos 10 servidores, visto que, quanto menor o tamanho da carreira, maior a probabilidade de uma observação isolada influenciar o cálculo das medidas agregadas. Por essa razão, do total de 146 carreiras civis, 17 foram retiradas da amostra. Ainda no tocante à seleção, cabe ressaltar que o Sistema Integrado de Administração de Pessoal (Sisap) não dispõe de dados de escolaridade e tempo de serviço dos militares, uma vez que o pagamento desses servidores é realizado por setor de recursos humanos próprio da instituição militar. Desse modo, o modelo trabalhou com dados relativos a 126 carreiras, que correspondem ao total de carreiras civis após a exclusão daquelas de tamanho inferior a 10 servidores e das carreiras administrativas da PMMG.

A seleção das variáveis considerou as dimensões levantadas pela literatura e a disponibilidade dos dados no Portal da Transparência e no Sisap-MG. Para captar as especificidades do setor público, foi necessário ampliar o modelo de Mincer com a inclusão de novas variáveis relacionadas com os recursos políticos das carreiras: a quantidade de servidores, o número de cargos comissionados de alto escalão, além de uma variável categórica para destacar as carreiras que desempenham atividades essenciais ao funcionamento do aparato estatal.

A definição dos cargos de alto escalão foi realizada pela análise da legislação e dos organogramas de órgãos e entidades estaduais, atribuindo pesos distintos de acordo com a posição dos cargos na hierarquia institucional. Os cargos de direção máxima foram contabilizados com peso 1, e os cargos de chefia intermediária - com nível hierárquico de superintendência ou similar -, com peso 1/3. Embora os cargos comissionados de alto escalão aumentem diretamente a remuneração dos indivíduos, o impacto endógeno dessa variável sobre a remuneração média da carreira é baixo, haja vista que o 
número de cargos selecionados é pequeno em relação ao total de servidores de cada carreira. ${ }^{4}$ Portanto, além do efeito direto que os cargos de alto escalão exercem sobre a remuneração, a operacionalização dessa variável busca dimensionar a proximidade das carreiras com o núcleo do poder decisório e a capacidade de influenciar as decisões políticas que as beneficiam.

Quanto às carreiras essenciais e exclusivas de Estado, no Poder Executivo estadual, foram destacadas as de Fazenda, Polícia Civil e Advocacia Geral do Estado, que desempenham, respectivamente, atividades de arrecadação tributária, de polícia e jurídicas.

Além das variáveis relacionadas com os recursos políticos das carreiras, o modelo incluiu uma variável categórica no intuito de operacionalizar a dimensão do prestígio social das profissões vinculadas a cursos superiores tradicionais. A maioria das carreiras de nível superior do governo de Minas Gerais não se vincula exclusivamente a uma graduação específica, com exceção das que exigem formação em medicina e direito, além de uma vinculada ao curso de administração pública da Fundação João Pinheiro. Portanto, para captar essa dimensão de análise, foram destacadas, com base na análise de Campos (1999), as carreiras de medicina e direito.

Por fim, no que diz respeito à discriminação social, foi incluída uma variável que mensura a composição por gênero. O Sisap não apresenta dados relacionados com os marcadores sociais de raça e de sexualidade dos servidores públicos, razão pela qual essas dimensões não foram incluídas na análise.

O quadro a seguir sintetiza a relação entre as teorias, as dimensões explicativas, as variáveis selecionadas e suas respectivas fontes de dados.

\section{QUADRO 2 SÍNTESE TEÓRICO-METODOLÓGICA DA OPERACIONALIZAÇÃO DAS VARIÁVEIS EXPLICATIVAS}

\begin{tabular}{|c|c|c|c|}
\hline Teoria & Dimensões relevantes & Variáveis de análise & Fonte de dados \\
\hline \multirow{2}{*}{$\begin{array}{l}\text { Teoria do capital } \\
\text { humano }\end{array}$} & Educação & Escolaridade média & Sisap \\
\hline & Experiência & Média do $n^{\circ}$ de anos de serviço & Sisap \\
\hline \multirow{3}{*}{$\begin{array}{l}\text { Teoria da segmentação } \\
\text { (especificidades do } \\
\text { setor público) }\end{array}$} & $\begin{array}{l}\text { Poder de pressão política das } \\
\text { carreiras mais numerosas }\end{array}$ & $\mathrm{N}^{0}$ de servidores & Portal da Transparência \\
\hline & Proximidade ao poder decisório & $\begin{array}{l}N^{0} \text { de cargos comissionados de alto } \\
\text { escalão }\end{array}$ & Portal da Transparência \\
\hline & $\begin{array}{l}\text { Poder de barganha e de monopólio } \\
\text { das carreiras essenciais/ } \\
\text { exclusivas de Estado }\end{array}$ & $\begin{array}{l}\text { Carreiras que desempenham } \\
\text { atividades essenciais/exclusivas de } \\
\text { Estado (variável binária) }\end{array}$ & Elaborado pelos autores \\
\hline Teoria da discriminação & Discriminação por gênero & Percentual de mulheres & Sisap \\
\hline $\begin{array}{l}\text { Sociologia das } \\
\text { profissões }\end{array}$ & Prestígio social & $\begin{array}{l}\text { Vínculo com cursos universitários de } \\
\text { medicina e direito (variável binária) }\end{array}$ & Elaborado pelos autores \\
\hline
\end{tabular}

Fonte: Elaborado pelos autores.

\footnotetext{
${ }^{4}$ Em apenas 1 das 126 carreiras da amostra, a remuneração dos cargos de alto escalão representou diretamente um impacto maior do que $10 \%$ na remuneração média da carreira.
} 
$\mathrm{Na}$ especificação do modelo, o impacto da escolaridade sobre a remuneração das carreiras foi subdividido em dois efeitos: o primeiro se refere às diferenças de exigência mínima de escolaridade para ingresso na carreira e o segundo se refere às diferenças incrementais por melhorias de escolaridade em relação ao nível mínimo. Tal subdivisão se justifica porque, além das diferenças de remuneração entre carreiras que exigem níveis distintos de qualificação, os incrementos de escolaridade dos servidores públicos estão associados a promoções e outros benefícios remuneratórios. Assim, foram criadas variáveis categóricas para classificar as carreiras de acordo com o nível mínimo exigido para ingresso, bem como uma variável contínua, que mensura a diferença entre o índice de escolaridade média das carreiras e o nível mínimo. ${ }^{5} \mathrm{O}$ Quadro 3 mostra a classificação das carreiras de acordo com as exigências mínimas de escolaridade, assim como os valores assumidos pelas variáveis binárias.

\section{QUADRO 3 CATEGORIZAÇÃO DAS CARREIRAS DE ACORDO COM AS EXIGÊNCIAS MÍNIMAS DE ESCOLARIDADE}

$\begin{aligned} & \text { Escolaridade mínima } \\ & \text { Valores assumidos pelas variáveis categóricas } \\ & \text { Nível fundamental }\end{aligned}$
"fundamental" $=1$
"Superior" $=0$
"prestígio" $=0$
"fundamental" $=0$
"superior" $=0$
Nível médio
"prestígio" $=0$
"fundamental" $=0$
"superior" $=1$
"prestígio" $=0$
Nível superior (com vínculo exclusivo com os cursos de direito e medicina)
"fundamental" $=0$
"superior" $=0$
"prestígio" $=1$

Fonte: Elaborado pelos autores.

Baseado no conjunto de variáveis selecionadas, o modelo de regressão foi especificado seguindo o formato usual log-linear:

$$
\begin{gathered}
\ln \text { sal_hora }=\beta_{0}+\beta_{1} \text { fundamental }+\beta_{2} \text { superior }+\beta_{3} \text { prestígio }+ \\
\beta_{4} \text { esc_inc }+\beta_{5} \text { temp_serv }+\beta_{6} \% \text { _mulheres }+\beta_{7} \text { alto_escalao }+\beta_{8} \ln \text { tamanho }+ \\
\beta_{9} \text { essenciais }+\mu
\end{gathered}
$$

\footnotetext{
${ }^{5} \mathrm{O}$ índice de escolaridade das carreiras foi calculado pela média ponderada da escolaridade dos servidores, que pode variar de 0 a 7, de acordo com as seguintes categorias: "Menos que $4^{\text {a }}$ série fundamental" (0), "Até 4 a série completa" (1), " 1 o grau completo" (2), "2º grau completo" (3), "Superior completo" (4), "Mestrado" (5), "Doutorado" (6) e "Pós-doutorado" (7).
} 
Na fórmula acima, "sal_hora" se refere à remuneração média da carreira por hora de trabalho; "fundamental" é a categoria das carreiras de nível fundamental; "superior" é a categoria das carreiras de nível superior, com exceção daquelas vinculadas aos cursos de direito e medicina; "prestígio" é a categoria das carreiras vinculadas aos cursos de medicina e direito; "esc_inc" se refere aos incrementos no índice de escolaridade em relação ao nível mínimo exigido pelas carreiras; "temp_serv" é o tempo médio de serviço; “\%_mulheres" é o percentual de mulheres na composição das carreiras; "alto_escalao" é o número de cargos de alto escalão; "tamanho" é o número de servidores que compõem a carreira; "essenciais" é a categoria que destaca as carreiras que desempenham atividades essenciais e exclusivas de Estado; e $\mu$ é o termo de erro aleatório.

Por fim, o cálculo da remuneração média das carreiras foi obtido por meio do Portal da Transparência e considerou as parcelas remuneratórias correspondentes ao cargo efetivo, à função e ao cargo comissionado, deduzidos os abatimentos pela aplicação do teto constitucional, acrescidos os jetons e a categoria "outros eventuais", que inclui gratificações, restituições, horas extras e outros pagamentos variáveis. Como as remunerações eventuais apresentam maiores oscilações temporais, foram calculadas, para cada carreira, as médias anuais dos eventuais recebidos em 2018, no intuito de suavizar o impacto dessas variações. Essa média foi incorporada às demais parcelas remuneratórias, que, por sua vez, mantiveram o mês de setembro de 2018 como referência.

\section{RESULTADOS}

Os resultados obtidos na análise de regressão e os testes de verificação da violação das premissas básicas do modelo se encontram no Apêndice. Em resumo, os testes não identificaram nenhum problema grave relativo à violação dessas premissas, o que confere maior confiabilidade aos resultados obtidos.

A análise dos resultados, apresentados no Quadro 4 do Apêndice, revela que todos os coeficientes estimados têm efeitos isolados estatisticamente significativos, ao nível de pelo menos $5 \%$ de significância. Portanto, pode-se inferir que as variáveis incluídas no modelo são relevantes para explicar as diferenças de remuneração média das carreiras. Ademais, os resultados encontrados estão alinhados com os argumentos levantados na revisão teórica, ou seja, as hipóteses teóricas não foram refutadas pelos sinais - positivos ou negativos - dos coeficientes estimados. $O \mathrm{R}^{2}$ de 0,8309 indica que o modelo foi capaz de explicar 83,09\% da variação na remuneração média das carreiras.

Em relação às exigências mínimas de escolaridade, os resultados confirmam uma relação positiva entre a educação formal e a remuneração dos servidores. Mantendo fixos os demais fatores, as carreiras de nível médio recebem, em média, 41,83\% acima das de nível fundamental e 105,79\% abaixo das de nível superior, com exceção daquelas vinculadas aos cursos de medicina e direito.

Nos casos em que a exigência de ensino superior está vinculada aos cursos de direito e medicina, o efeito líquido sobre a remuneração média das carreiras é maior. Controlando o efeito dos outros fatores, as carreiras de direito e medicina têm remuneração média 312,18\% acima das de nível médio e $100,29 \%$ maior que as demais de nível superior. Esse resultado reforça os argumentos levantados pelos autores da sociologia das profissões, que discutem o prestígio social e as estratégias de dominação de determinados grupos profissionais na sociedade. ${ }^{6}$

\footnotetext{
${ }^{6}$ Há uma possível limitação na interpretação do resultado para o caso das carreiras que se vinculam ao curso de direito. Todas elas também foram classificadas como carreiras essenciais de Estado, o que pode gerar um problema de multicolinearidade, ainda que os testes do modelo não tenham detectado problemas de multicolinearidade entre as variáveis explicativas.
} 
O efeito da escolaridade sobre a remuneração das carreiras não se expressa somente nas exigências mínimas para ingresso, mas também nos incrementos de escolaridade, que acarretam promoções salariais automáticas e outros ganhos remuneratórios. De acordo com os resultados previstos pelo modelo, se todos os servidores de determinada carreira evoluírem um nível de escolaridade, espera-se que a remuneração média dessa carreira aumente $42,42 \%$, mantendo constante os demais fatores.

Conforme se discutiu antes, há um debate teórico importante entre a teoria do capital humano e outras abordagens teóricas acerca dos mecanismos que vinculam a escolaridade a recompensas econômicas. Embora as explicações tenham fundamentações distintas, elas contribuem, em alguma medida, para compreender o fato de a escolaridade ser um importante determinante das diferenças salariais não só no setor privado, mas também no público.

Outro fator, também relacionado com a teoria do capital humano, é o tempo de serviço, que, no setor público, é um critério básico de progressão salarial e está associado à incorporação de outros adicionais, como os quinquênios. A estimativa da regressão indica que, mantendo fixos os demais fatores, a remuneração média de uma carreira aumentaria $3,18 \%$ para cada ano adicional no tempo médio de serviço dos seus servidores.

A desigualdade de remuneração das carreiras do setor público, entretanto, também é influenciada por outras dimensões políticas e sociais. Quanto à questão da discriminação social, o modelo estimou o efeito da composição por gênero na remuneração das carreiras. O resultado encontrado prevê uma redução de $0,35 \%$ na remuneração média das carreiras para um aumento de $1 \%$ no percentual de mulheres que as compõem.

Para explicar essa relação negativa, em primeiro lugar, pode-se argumentar que a divisão sexual do trabalho numa sociedade patriarcal atribui às mulheres a responsabilidade por atividades relacionadas com cuidados e tarefas domésticas, menos valorizadas pelo mercado de trabalho, enquanto as atividades de maior prestígio social são majoritariamente executadas por homens. Tal divisão sexual do trabalho molda as relações sociais e o horizonte de expectativas de homens e mulheres, assim como gera desigualdades relacionadas com as possibilidades de conciliação entre vida profissional e as atribuições domésticas e familiares. Especificamente em relação ao setor público, é preciso considerar que os concursos mais valorizados são mais concorridos e exigem maior tempo de estudos e preparação. Se as mulheres dedicam, em média, mais horas de trabalho doméstico e de cuidados do que os homens, a disponibilidade de tempo e as condições de competição para ingresso nas carreiras mais bem remuneradas são desiguais. Além disso, mesmo após o ingresso no setor público, a dupla jornada de trabalho pode afetar o tempo disponível que as servidoras dispõem para adquirir algumas qualificações extras, o que prejudica o desenvolvimento na carreira. Por fim, a discriminação por gênero pode operar também na distribuição desigual dos cargos comissionados e das funções gratificadas, o que se revela pela constatação de que a maioria dos cargos políticos de alto escalão é ocupado por homens.

Todas as variáveis analisadas até aqui - escolaridade, prestígio social dos cursos de medicina e direito, tempo de serviço e percentual de mulheres - representam dimensões de análise que não são exclusivas do setor público. Além dessas, os resultados revelam que os recursos políticos das carreiras também são fatores importantes para explicar as diferenças de remuneração no setor público. 
Conforme já discutido, as carreiras que desempenham atividades exclusivas e essenciais ao funcionamento do aparato estatal detêm um importante recurso político, uma vez que o Estado apresenta uma dependência vital quanto às funções por elas desempenhadas. Além disso, essas carreiras não têm correspondência no setor privado, o que confere a elas um poder de monopólio. Essas carreiras apresentaram, em média, uma remuneração 48,82\% maior que as demais, mantendo constantes as outras variáveis. Esse valor revela que as carreiras da Secretaria da Fazenda, da Polícia Civil e da Advocacia Geral do Estado recebem remunerações substancialmente maiores, mesmo quando comparadas com outras com o mesmo nível de escolaridade, tempo médio de serviço e composição por gênero.

Além da natureza da atividade desempenhada, o acesso ao núcleo do poder decisório é outro recurso político das carreiras. O impacto desse recurso sobre a remuneração pode acontecer de duas maneiras distintas. Em primeiro lugar, as carreiras mais próximas ao poder dispõem de maior capacidade de influenciar as decisões políticas que beneficiam seus servidores, como a aprovação de leis específicas concedendo benefícios remuneratórios diferenciados. Por outro lado, a ocupação de cargos comissionados de alto escalão aumenta diretamente a remuneração dos servidores públicos. O valor do coeficiente prevê que a remuneração média das carreiras aumente 2,31\% para cada cargo adicional de alto escalão, mantendo constante os valores dos outros fatores. Esse efeito é, em média, cerca de cinco vezes maior do que o ganho direto de remuneração em razão de ocupação do cargo comissionado, o que reforça o argumento de que o acesso aos cargos de alto escalão gera não apenas um ganho direto de remuneração aos servidores que ocupam tais cargos, mas expressam diferenças de acesso ao poder, que se traduzem em benefícios remuneratórios em favor das carreiras mais próximas do núcleo decisório.

Outro recurso político mencionado por Marconi (2010) é o tamanho das carreiras. O modelo estima um crescimento de $0,04 \%$ na remuneração média para um aumento marginal de $1 \%$ no número de servidores, mantendo fixos os demais fatores. Supondo que duas carreiras se diferenciem entre si somente pelo tamanho, sendo que uma delas conta com 200 servidores e a outra, com 2 mil, o modelo prevê que a remuneração média da carreira mais numerosa seja cerca de $10,31 \%$ mais elevada do que a da menor, o que corrobora a ideia de que as carreiras mais numerosas têm maior capacidade de exercer pressões políticas para obter suas reivindicações.

Os resultados encontrados, portanto, reforçam o argumento de que as disparidades de remuneração no funcionalismo público são determinadas não apenas por diferenças de qualificação e de experiência profissional, mas reproduzem desigualdades que marcam a sociedade brasileira. Ademais, a estrutura relativa de salários no setor público tem especificidades em relação ao privado e é influenciada pelos recursos políticos disponíveis aos segmentos do corpo burocrático. Para ilustrar essas conclusões, os gráficos abaixo mostram as correlações entre as variáveis de interesse e a remuneração média das carreiras, controladas pelo nível de escolaridade. Neles, cada ponto representa uma carreira do Estado, o tamanho dos pontos reflete o número de servidores e a linha de tendência representa a correlação esperada entre escolaridade média e remuneração média das carreiras. Diferentemente do modelo de regressão linear múltipla, tais gráficos não permitem captar o efeito simultâneo de todas as variáveis explicativas, mas possibilitam uma melhor visualização descritiva da amostra trabalhada na pesquisa. 


\section{GRÁFICO 5 VARIÁVEIS DE INTERESSE E REMUNERAÇÃO MÉDIA DAS CARREIRAS, CONTROLADAS PELO NÍVEL DE ESCOLARIDADE}

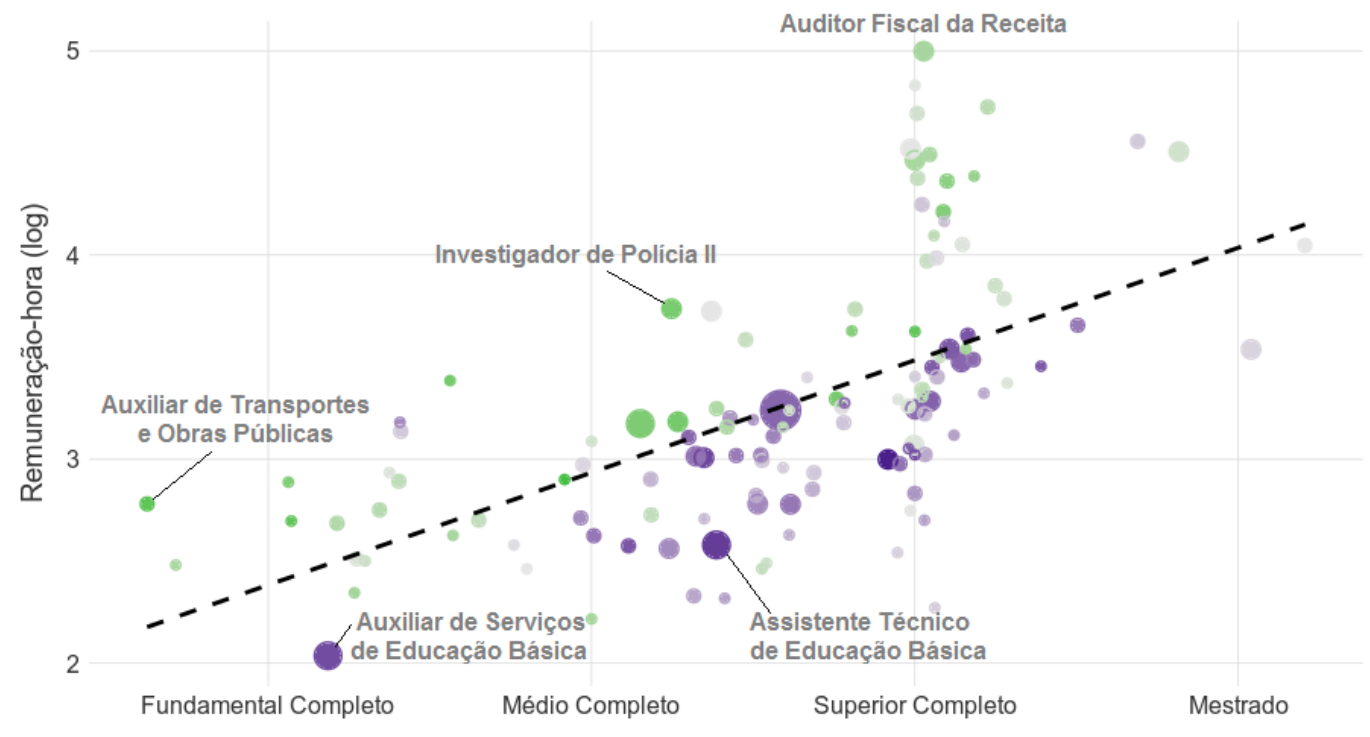

Escolaridade Média

Percentual de Mulheres:

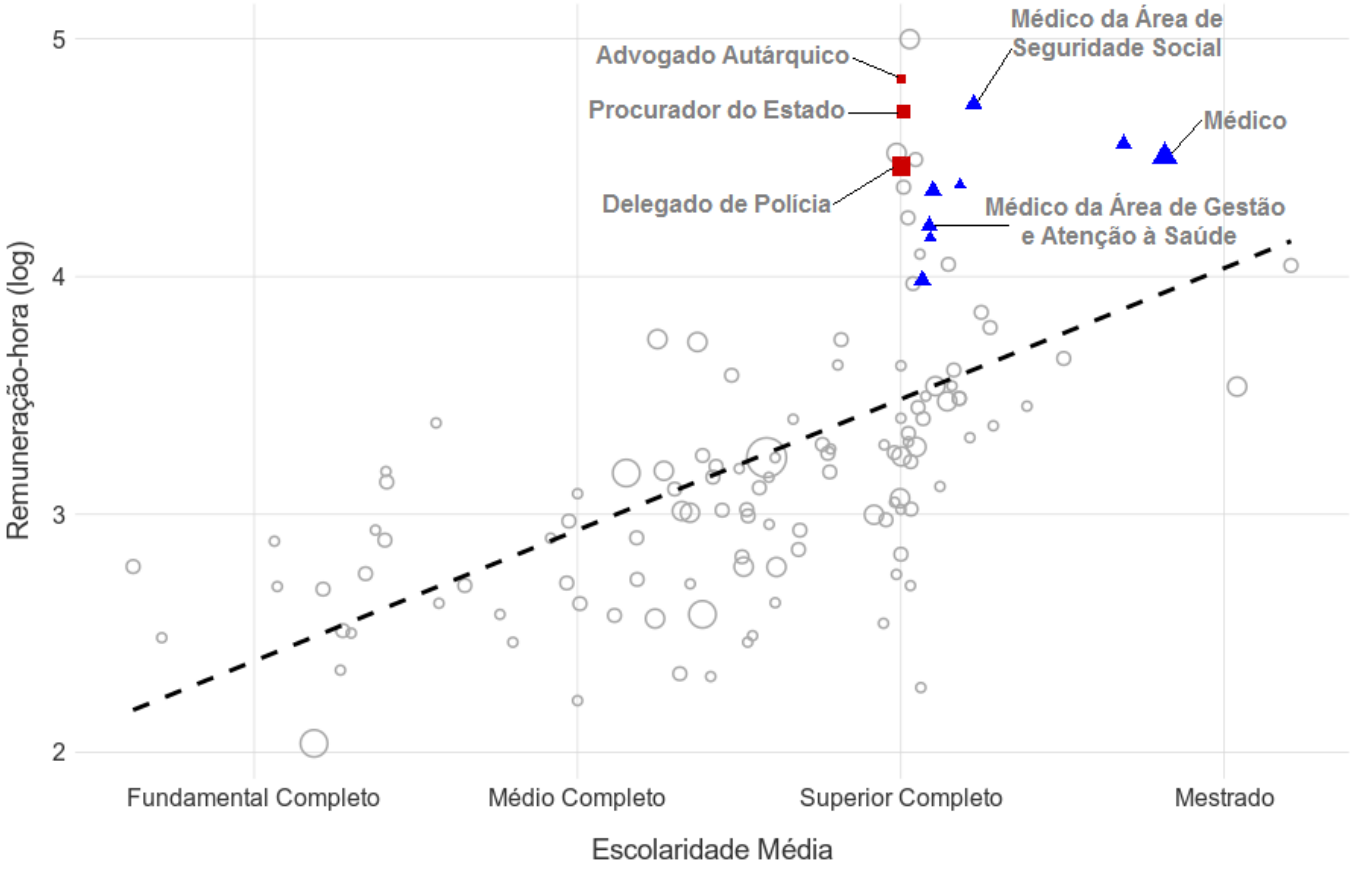


RAP $\quad$ Determinantes da desigualdade salarial entre as carreiras do governo de Minas Gerais
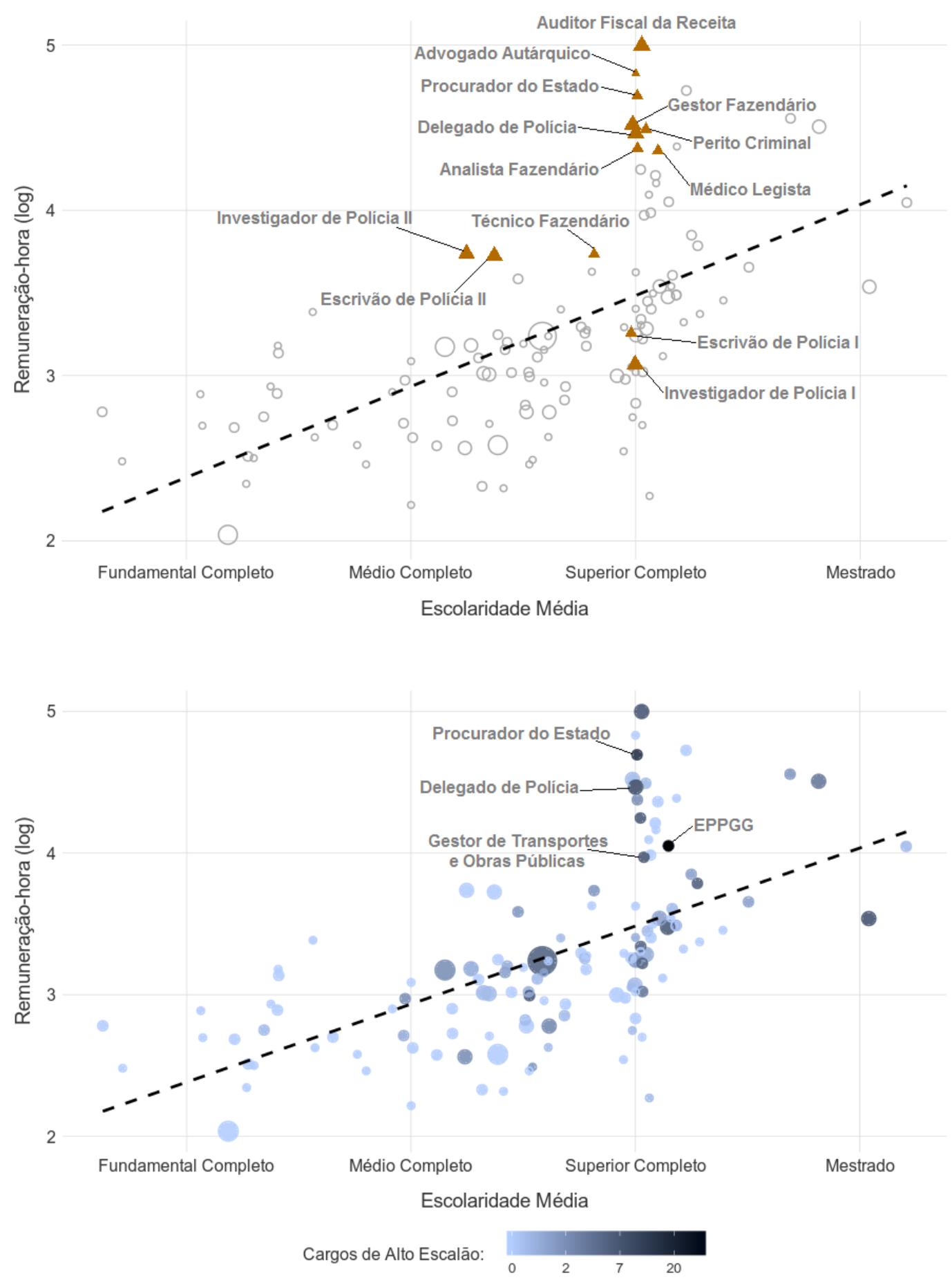

Fonte: Elaborado pelos autores. 


\section{CONCLUSÃO}

Este trabalho se propôs a investigar os determinantes das diferenças de remuneração entre as carreiras do Poder Executivo do estado de Minas Gerais. Para isso, foram resgatadas diferentes abordagens teóricas acerca do tema "determinação dos salários", além de considerar as especificidades do setor público. O exame dessas particularidades sugere que os fatores políticos são muito importantes para a compreensão da estrutura de salários relativos do setor público, uma vez que os grupos burocráticos têm capacidades distintas de influenciar as decisões do governo, de acordo com os recursos políticos de que dispõem. Dessa forma, a análise foi guiada pela hipótese de que as diferenças salariais no setor público refletem não apenas a qualificação e a experiência profissional, como também reproduzem outros aspectos da desigualdade social e constituem uma manifestação concreta do processo de estratificação da burocracia pública, sendo determinada, ainda que não exclusivamente, pelos recursos políticos que as múltiplas categorias do aparelho burocrático mobilizam.

Assim, foi realizada uma análise de regressão linear, que buscou estimar o efeito líquido dos principais determinantes da remuneração média das carreiras. Além das variáveis de controle escolaridade e tempo de serviço -, foram incluídas no modelo as seguintes variáveis explicativas: percentual de mulheres, vínculo com cursos superiores tradicionais, número de cargos comissionados de alto escalão, natureza típica da atividade desempenhada e quantidade de servidores por carreira. Os resultados encontrados corroboram a hipótese adotada, pois as variáveis de interesse se mostraram estatisticamente significativas para explicar as diferenças de remuneração entre as carreiras.

Entre as limitações do trabalho, além da indisponibilidade dos dados de escolaridade dos militares no Sisap-MG e da ausência de dados referentes aos marcadores sociais de raça e sexualidade, a pesquisa faz uma análise de um ponto específico no tempo e, por essa razão, não mostra as variações ao longo de um período temporal. Para aprofundar o estudo, novas análises podem comparar as estruturas salariais em diferentes contextos econômicos e mandatos de governo, uma vez que a concessão de reajustes salariais pode revelar as prioridades dos governantes, que, a depender do contexto político e econômico, têm maior ou menor autonomia em relação à política de remuneração. Os diferentes governos podem optar por valorizar algumas carreiras consideradas estratégicas ou determinadas áreas de políticas públicas em detrimento de outras. Além disso, a política de remuneração pode ter diferentes objetivos, como atração e retenção de mão de obra qualificada e estímulo à produtividade, com foco maior ou menor na questão da equidade, contribuindo para corrigir ou reproduzir desigualdades e privilégios históricos que marcam a constituição da sociedade brasileira. Por fim, é importante compreender os processos históricos de formação e diferenciação das instituições estatais, assim como a relação entre burocratas e governantes, que inclui os mecanismos de interação, as estratégias políticas, o ambiente institucional em que ocorrem as negociações e a relação da burocracia com os partidos políticos e com outros grupos de interesse. 


\section{REFERÊNCIAS}

Abrucio, F., \& Loureiro, M. (2018). Burocracia e ordem democrática: desafios contemporâneos e experiência brasileira. In R. Pires, G. Lotta, \& V. Oliveira (Orgs.), Burocracia e políticas públicas no Brasil. Brasília, DF: Ipea.

Abrucio, F., Pedroti, P., \& Pó, M. (2010). A formação da burocracia brasileira: a trajetória e o significado das reformas administrativas. In F. Abrucio, M. Loureiro, \& R. Pacheco (Orgs.), Burocracia e política no Brasil: desafios para a ordem democrática no século XXI. São Paulo, SP: FGV.

Bonelli, M., \& Oliveira, F. (2003). A política das profissões jurídicas: autonomia em relação ao mercado, ao estado e ao cliente. Revista de Ciências Sociais, 34(1), 99-114.

Bresser-Pereira, L. C. (1998). A reforma do estado dos anos 90: lógica e mecanismos de controle. Lua Nova: Revista de Cultura e Política, 45, 49-95.

Cavalcante, P., \& Carvalho, P. (2017). Profissionalização da burocracia federal brasileira (1995-2014): avanços e dilemas. Revista de Administração Pública, 51(1), 1-26.

Coelho, E. (1999). As profissões imperiais: advocacia, medicina e engenharia no Rio de Janeiro (1822-1930). Rio de Janeiro, RJ: Record.

Collins, R. (1971) Functional and conflict theories of educational stratification. American Sociological Review, 36(6), 1002-1019.

Daré, E. (2011). Desigualdade da distribuição de renda no Brasil: a contribuição dos rendimentos do funcionalismo público (Dissertação de Mestrado). Universidade Estadual de Campinas, Campinas, SP.

Fernandes, C., \& Palotti, P. (2019). Professionalizing bureaucracy and building state capacities: are there unequal advances in Brazilian public administration? Revista de Administração Pública, 53(4), 687-710.

Fernandes, R. (2002). Desigualdade salarial: aspectos teóricos. In C. Corseuil (Ed.), Estrutura salarial: aspectos conceituais e novos resultados para o Brasil. Rio de Janeiro, RJ: Ipea.

Gouvêa, G. (1994). Burocracia e elites burocráticas no Brasil. São Paulo, SP: Pauliceia.

Hoffmann, R. (2013). Transferências de renda e desigualdade no Brasil (1995-2011). In T. Campello,
\& M. Neri (Orgs.), Programa Bolsa Família: uma década de inclusão e cidadania. Brasília, DF: Ipea.

Instituto de Pesquisa Econômica Aplicada. (2018). Atlas do Estado Brasileiro. Recuperado de http:// www.estado.ipea.gov.br

Lei n. 19.576, de 16 de agosto de 2011. (2011). Reajusta os valores das tabelas de vencimento básico das categorias que menciona. Belo Horizonte, MG: Diário Oficial do Estado de Minas Gerais.

Lei n. 22.062, de 20 de abril de 2016. (2016). Altera a Lei $21.710 / 2015$, que dispõe sobre a política remuneratória das carreiras do grupo de atividades de educação básica do Poder Executivo, altera a estrutura da carreira de professor de educação básica e dá outras providências. Belo Horizonte, MG: Diário Oficial do Estado de Minas Gerais.

Lopez, F., \& Silva, T. (2019). Filiações partidárias e nomeações para cargos da burocracia federal (1999-2018). Revista de Administração Pública, 53(4), 711-731.

Marconi, N. (2001). A formação dos salários nos setores público e privado (Tese de Doutorado). Fundação Getulio Vargas, São Paulo, SP.

Marconi, N. (2010). Uma radiografia do emprego público no Brasil. In F. Abrucio, M. Loureiro, \& R. Pacheco (Orgs.), Burocracia e política no Brasil: desafios para a ordem democrática no século XXI. São Paulo, SP: FGV.

Modesto, P. (2016). O sentido constitucional de carreira no serviço público. Revista Eletrônica de Direito do Estado, 49, 1-9. Recuperado de http:// www.direitodoestado.com.br/rede/edicao/49

Monteiro, L. M. (2013). Reforma da administração pública e carreiras de Estado: o caso dos especialistas em políticas públicas e gestão governamental no Poder Executivo federal. Revista de Administração Pública, 47(5), 1117-1144.

Olivieri, C. (2011). Os controles políticos sobre a burocracia. Revista de Administração Pública, 45(5), 1395-1424.

Pacheco, R. (2010). Profissionalização, mérito e proteção da burocracia no Brasil. In F. Abrucio, M. Loureiro, \& R. Pacheco (Orgs.), Burocracia e política no Brasil: desafios para a ordem democrática no século XXI. São Paulo, SP: FGV. 
Santos, A. (2011). Principais abordagens sociológicas para análise das profissões. Revista Brasileira de Informação Bibliográfica em Ciências Sociais, 71, 25-43.

Santos, C., Cavalcante, C., Martins, F., Lacerda, L., \& Schettini, B. (2016). Evolução do emprego público nos governos subnacionais brasileiros no período 2004-2014. Brasília, DF: Ipea.

Secretaria do Tesouro Nacional. (2021). RGF em foco: Estados + Distrito Federal. Brasília, DF: Autor.

Souza, P., \& Medeiros, M. (2013). Diferencial salarial público-privado e desigualdade de renda per capita no Brasil. Estudos Econômicos, 43(1), 5-28.

Souza, S., Bessa, D., Margonato, R., \& Ferreira, C. (2017). Rendimento do trabalho, posições na ocupação e desigualdade da renda no Paraná. Ensaios FEE, 37(4), 925-946.

Vaz, D., \& Hoffmann, R. (2007). Remuneração nos serviços no Brasil: o contraste entre funcionários públicos e privados. Economia e Sociedade, 16(2), 199-232.

Ventura, T., \& Cavalieri, M. A. R. (2021). Diferenciais de salários dentro do Poder Executivo brasileiro: uma análise de cluster. Revista de Administração Pública, 55(4), 757-781.

Woodhall, M. (1987). Human capital concepts. In G. Psacharopoulos (Ed.), Economics of education: research and studies. Oxford, UK: Pergamon.

\section{Rodolfo Pinhón Bechtlufft}

https://orcid.org/0000-0001-6876-3264

Graduação em Ciências Econômicas pela Universidade Federal de Minas Gerais (UFMG) e em Administração Pública pela Escola de Governo da Fundação João Pinheiro (FJP). E-mail: rbechtlufft@msn.com

\section{Bruno Lazzarotti Diniz Costa}

\section{https://orcid.org/0000-0001-5972-4175}

Doutor em Ciências Humanas: Sociologia e Política pela Universidade Federal de Minas Gerais (UFMG); Professor e pesquisador da Escola de Governo da Fundação João Pinheiro (FJP).

E-mail: bruno.diniz@fjp.mg.gov.br 


\section{APÊNDICE}

\section{Resultados e testes do modelo}

\section{QUADRO 4 RESULTADOS DA REGRESSÃO}

\begin{tabular}{lcc} 
Variáveis & Coeficientes & P-Valor \\
\hline "fundamental" & $-0,5418$ & $3,32 \mathrm{e}-10\left(^{\star \star \star}\right)$ \\
"superior" & 0,7217 & $<2 \mathrm{e}-16\left(^{\star \star \star}\right)$ \\
"prestígio" & 1,4163 & $<2 \mathrm{e}-16\left(^{\star \star \star}\right)$ \\
"esc_inc" & 0,3536 & $1,12 \mathrm{e}-05\left(^{\star \star \star}\right)$ \\
"temp_serv" & 0,0313 & $3,64 \mathrm{e}-13\left(^{\star \star \star}\right)$ \\
"\%_mulheres" & $-0,0035$ & $0,01268\left(^{\star}\right)$ \\
"alto_escalao" & 0,0228 & $0,00293\left(^{\star \star}\right)$ \\
"In_tamanho" & 0,0426 & $0,00654\left(^{\star \star}\right)$ \\
"essenciais" & 0,3976 & $2,80 \mathrm{e}-05\left(^{\star \star \star}\right)$ \\
(Intercepto) & 2,2151 & $<2 \mathrm{e}-16\left(^{(\star \star}\right)$
\end{tabular}

$\mathrm{R}^{2}=0,8309$

$\mathrm{R}^{2}$ ajustado $=0,8177$

Teste $\mathrm{F}=62,8$, p-valor $<2.2 \mathrm{e}-16\left(^{* * *}\right)$

Níveis de significância: $\left({ }^{*}\right) \mathrm{p}<0,05 ;\left(^{* *}\right) \mathrm{p}<0,01 ;\left(^{* * *}\right) \mathrm{p}<0,01$

Fonte: Elaborada pelos autores.

\section{QUADRO 5 RESUMO DOS TESTES FORMAIS DE VIOLAÇÃO DAS PREMISSAS DO MODELO}

\begin{tabular}{|c|c|c|c|}
\hline Premissa & Teste formal & Resultado do teste & Interpretação \\
\hline $\begin{array}{l}\text { Normalidade na distribuição } \\
\text { dos resíduos }\end{array}$ & Shapiro-Wilk & $p$-valor $=0.2245$ & Se $p$-valor $>0.05$, premissa não violada \\
\hline $\begin{array}{c}\text { Ausência de multicolinearidade } \\
\text { entre os regressores }\end{array}$ & FIV & $\begin{array}{c}\text { Menor FIV: } 1.1327 \text { ("alto_ } \\
\text { escalao") } \\
\text { Maior FIV: } 2.0525 \text { ("temp_serv") }\end{array}$ & Se FIV < 10, premissa não violada \\
\hline $\begin{array}{c}\text { Ausência de } \\
\text { heterocedasticidade }\end{array}$ & Breusch-Pagan & $p$-valor $=0.4684$ & Se $p$-valor $>0.05$, premissa não violada \\
\hline $\begin{array}{c}\text { Ausência de autocorrelação } \\
\text { entre os resíduos }\end{array}$ & Durbin-Watson & 2.0666 & $\begin{array}{l}\text { Com } 126 \text { observações e } 9 \text { regressores, } \\
\text { a premissa não é violada se o resultado } \\
\text { estiver entre } 1.86435 \text { e } 2.13565\end{array}$ \\
\hline Correta especificação do modelo & Reset & $p$-valor $=0.0933$ & Se $p$-valor $>0.05$, premissa não violada \\
\hline
\end{tabular}

Fonte: Elaborado pelos autores. 


\section{GRÁFICO 6 HISTOGRAMA DE DISTRIBUIÇÃO DOS RESÍDUOS PADRONIZADOS}

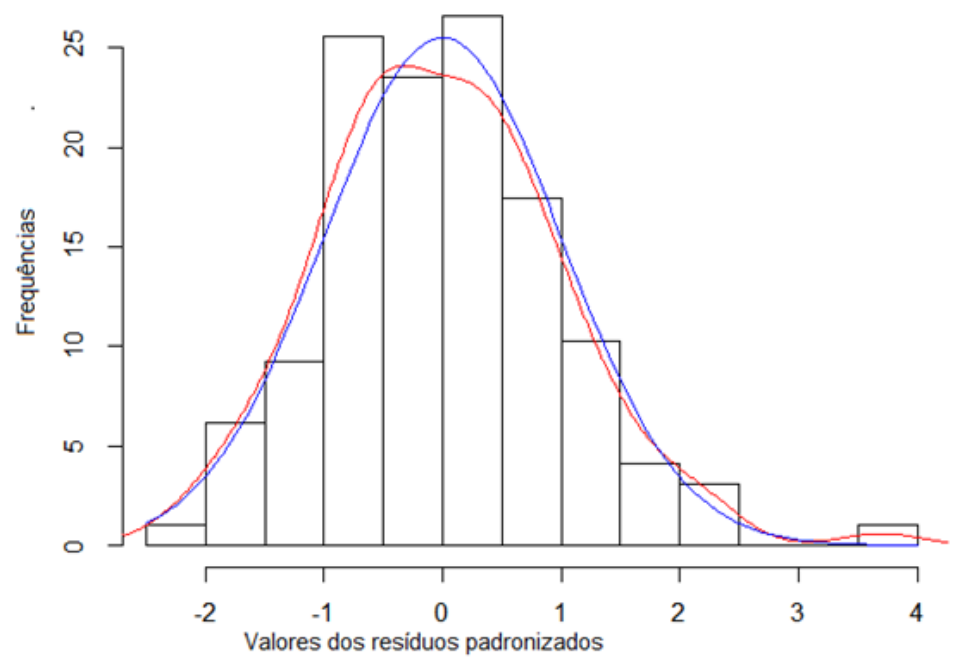

Fonte: Elaborado pelos autores.

FIGURA 1 MATRIZ DE CORRELAÇÕES DAS VARIÁVEIS EXPLICATIVAS

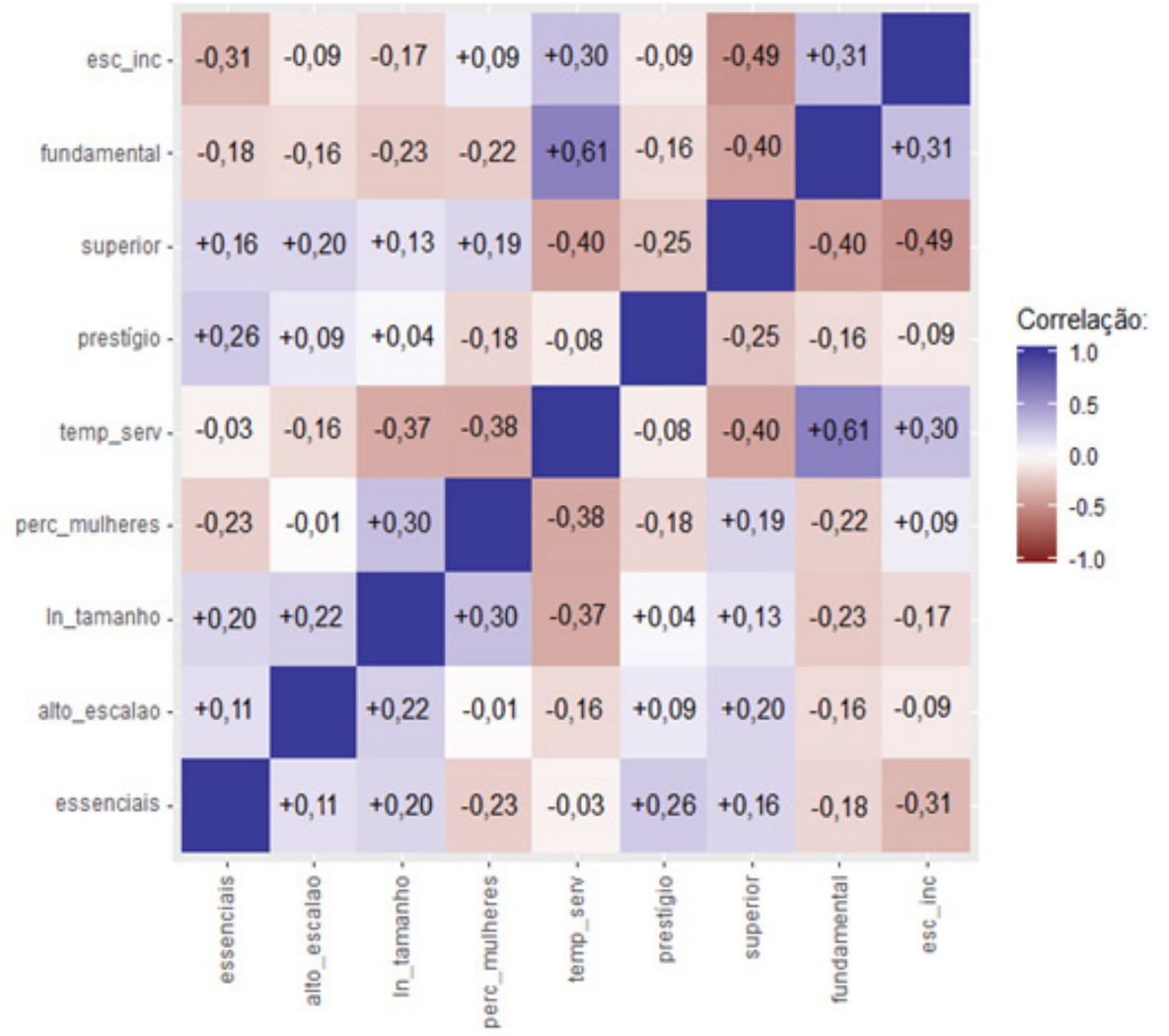

Fonte: Elaborada pelos autores.

ReVISta de Administração PÚblica | Rio de Janeiro 55(4): 836-860, jul. - ago. 2021 
RAP $\quad$ Determinantes da desigualdade salarial entre as carreiras do governo de Minas Gerais

FIGURA 2 DIAGRAMA DE DISPERSÃO DOS RESÍDUOS PADRONIZADOS EM RELAÇÃO AOS VALORES PREVISTOS PELO MODELO

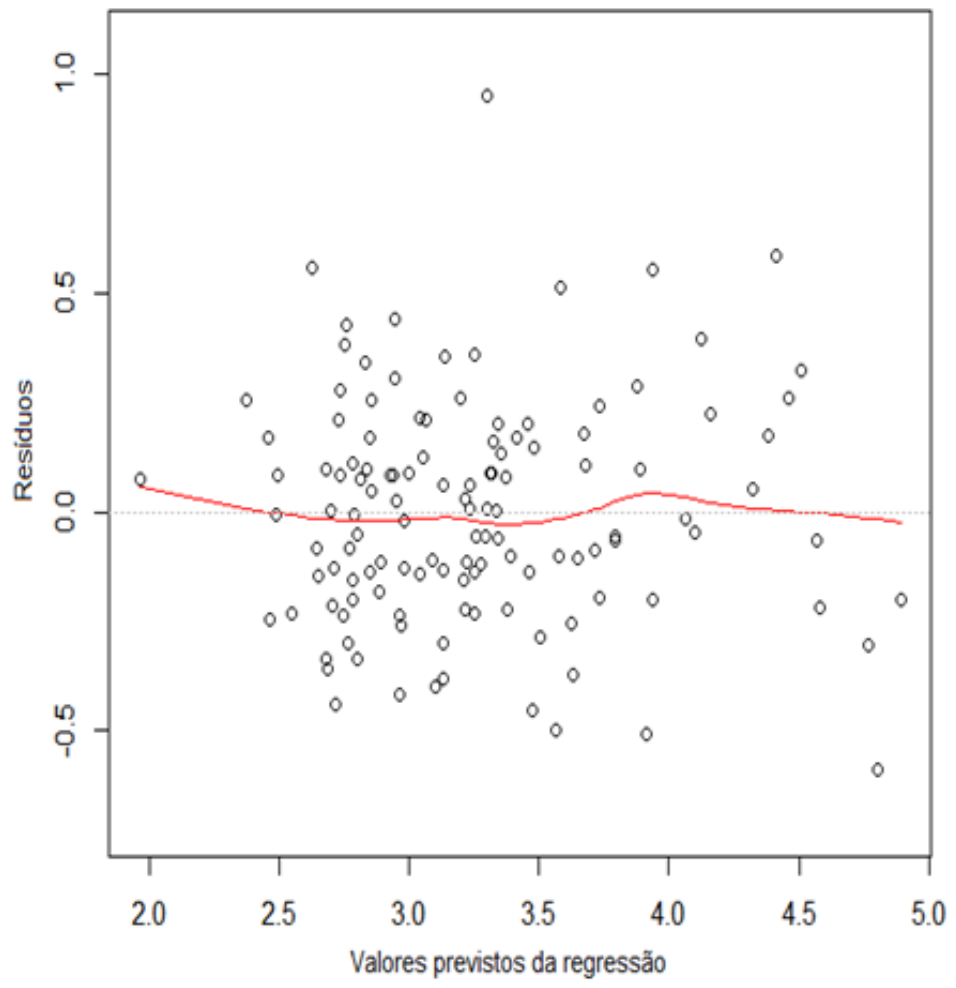

Fonte: Elaborada pelos autores. 


\section{GRÁFICO 7 HISTOGRAMAS DE DISTRIBUIÇÃO DAS VARIÁVEIS QUANTITATIVAS DO MODELO}

Histograma de "In_sal_hora"

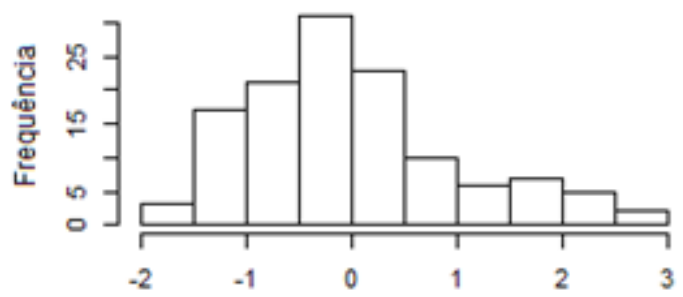

Histograma de "temp_serv"

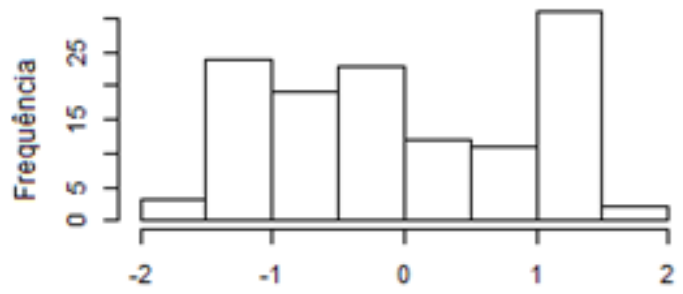

Histograma de "In_tamanho"

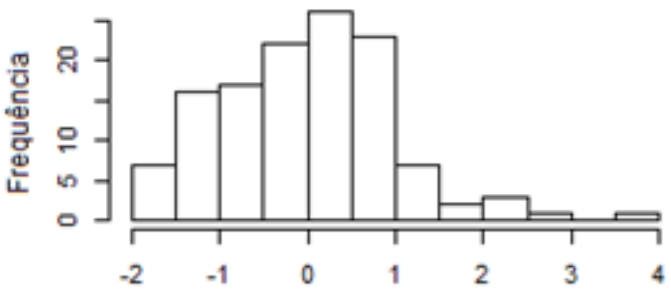

Histograma de "esc_inc"

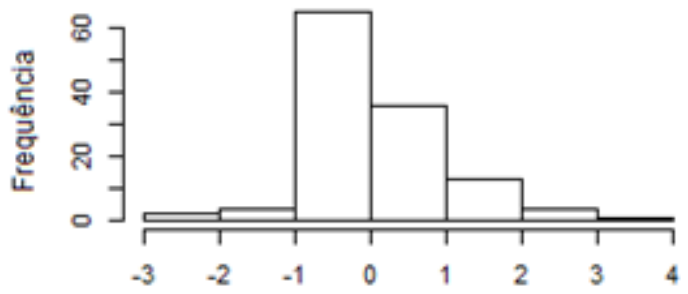

Histograma de "perc_mulheres"

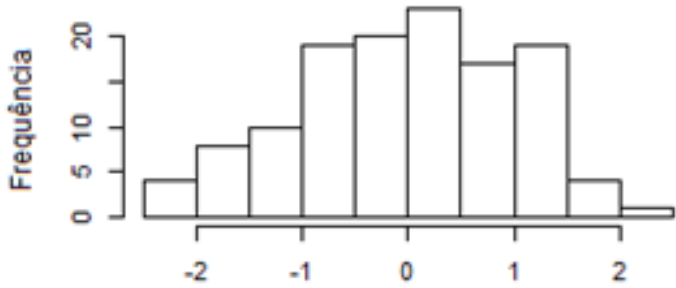

Histograma de "alto_escalao"

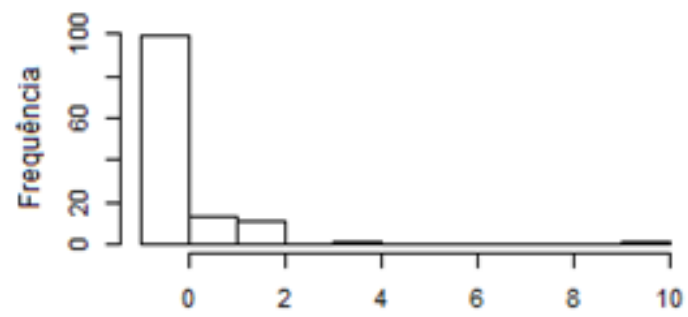

Fonte: Elaborado pelos autores. 